\title{
Further on Down the Digital Road: narrative design and reading pleasure in five New Media Writing Prize narratives.
}

\section{Introduction}

In 2006 and 2010 I published papers (Pope 2006, Pope 2010), reporting on a study in which I analysed readers' responses to several digital-interactive narratives (which, for convenience I will call 'hyperliterature' hereafter). In the 2010 paper, I formed a set of writing and design guidelines for such narratives, intended to be of use to writers, academics, and teachers looking for ways to understand the changing forms of digital storytelling, which, then and now, can surprise, delight, and puzzle.

Over two decades, following the arrival of pioneering hypertexts such as Michael Joyce's afternoon, a story (1987), there had been a lengthy debate around the pleasures and pains of hyperliterature: great enthusiasm (Bolter 2001, Douglas 2000, Landow 1997, Murray 1997) and deep scepticism (Birkerts 1997, Miall 1998, 1999, 2003, Miller 1998) seemed to leave the future of this embryonic art-form in doubt. Furthermore, I had found that, despite all the early interest and excitement, there was little awareness amongst the broader reading public - people who loved novels, plays, films, and so on, were not very much buying and/or reading interactive 'literature' for digital devices. I wanted to understand why this was the case.

The debate over a future for hyper-literature has largely subsided. Although some academics, for example, Mangen and van der Weel (2015), are still doubtful that hyper-literature can offer the reading pleasures afforded by non-interactive literature, I have no concern that hyper-literature might have no future. Hyper-text has evolved, alongside the progress of software and hardware, into hypermedia, where interactive fiction now is as much interested in combinations of media modes as it is with the hyper-linking of lexias.

Studies such as Ensslin (2014), and Koenitz et al (2013) are useful, as we seek to understand and categorise the diverse range of digital literary art being created. I note that Punday (2011) advocates a return to the term 'multimedia' to help describe the hard-to-define works we are seeing, and, certainly, Andy Campbell, Christine Wilks, Kate Pullinger, Rindon Johnson, and Jason Nelson are just a few examples of authors worldwide who use graphics, video, animation, and sound, along with text, interactivity and hyper-linking. Furthermore, they all illustrate what Ensslin has termed the 'L-L continuum' (Ensslin 2014, p43), where gaming and literary qualities mix and merge. 'Readers' are now being involved in very diverse cognitive and ergodic activities, by comparison with the experience of early hypertexts such as Victory Garden (Moulthrop 1991), or Patchwork Girl (Jackson 1995), which were almost entirely composed of hyper-linked text.

Hyper-literature has thus not disappeared: innovation is vigorous, and some forms are now selling in good numbers, e.g. PRY (Gorman and Cannizarro 2014), which has featured in Apple's top 25 best-selling apps, and has received high praise, e.g. 'Everyone interested in the contemporary state or future of literature as a hybrid tactile mediated experience should experience Pry’ (Los Angeles Review of Books, on the Apple app store). Other outstanding works are reaching a wide audience, for example Inanimate Alice (The Bradfield Company, 2006-2015), which is read and used widely in schools.

Nonetheless, I still perceive an overall lack of awareness and interest outside of the academy and the writers themselves. Traditional publishers have been slow to take up the challenge of making hyper-literature available and accessible, leaving one or two notable developers (for example Touch Press and Nosy Crow) to trail-blaze, and solo artists to experiment and innovate. Ryan (2006, p99) has argued that 'it will... take a seamless (some will say miraculous) convergence of bottom-up [reader] input and top-down [author] design to produce well-formed narrative patterns'. And while there are recent interesting and innovative interactive narratives that are approaching this goal, I believe there are still issues to be considered, around the relationship between non-trivial activity (Aarseth 1997) and reader absorption.

I have argued previously that the act of reading hyper-literature can be enjoyable in many ways. But I also agreed with the sceptics insofar as I found in 2006 and 2010 that the experience of highly non-linear narrative progress, combined with user-unfriendly interfaces and disruptive interactivity, could break the desirable balance of effort and reward, a balance that leads to flow, essential to reading pleasure (Csikszentmihalyi 1975, 2002, Klimmt et al 2012, Nell 1988, Roth et al 2011). In this study I investigate whether more recent hyperactive narratives, with all their multi-media enticements, still present these challenges to readers.

With the aim of offering some contemporary insights into the relationship between interactivity design and reader enjoyment, this paper reviews a very specific set of interactive narratives - those 
which have been shortlisted for the international New Media Writing Prize. This is an annual international competition which looks for the following in entries:

- ' Innovative use of new (digital) media/transmedia to create an engaging, satisfying narrative, or poem, or as-yet-unspecified form.

- $\quad$ 'Ease of accessibility for the reader/viewer.

- $\quad$ Effective use of interactive elements.

- 'A great example of how new media can do things traditional media can’t.

- 'The potential to reach out to a wide audience (i.e. not just specialist interest groups'

(extract from FAQ at www.newmediawritingprize.co.uk )

These are works which one might suppose demonstrate the best of everything that new-media storytelling can offer, and which therefore might provoke positive responses from readers other than the competition judges. I revisit my earlier writing guidelines (Pope 2010) in the light of technical and creative developments between 2010 and 2015, using the responses of volunteer readers to enhance my own critical evaluation of the pieces under discussion.

Overall, I argue that many of the issues I previously found to be a barrier to readers have been overcome, but that there are still problems which writers/artists need to consider.

\section{Methodology for the reader survey}

\subsection{Overview}

Replicating the methods reported upon in 2006 and 2010, relevant reading theory and empirical research was interpreted and modified to devise an overarching methodology (Richards 1929; Holland 1975; Iser 1976; Fish 1970, 1980; Nell 1988; Mangen 2008; Miall and his colleagues 1994, 1995, 1999, 2001, 2003; Thury 1998; Zyngier (2003).

The reader of hyper-litearature is also a 'user' (Klimmt et al 2012; Livingstone 2004; Murray1997, Roth et all 2011), in that the hyper-reader must engage in significant non-trivial (Aarseth 1997) activity before the narrative can come to life in the imagination; so I have also referred to interface usability studies from the field of human-computer interface design (Ebling and John 2000; Kjeldskov et al 2004; Nielsen 1989; Nielsen et al 2002; Pace 2003; Petersen 1998; Wright and Monk 1990), which I modified to suit a study of hyper-reading.

\subsection{Methods}

Again, as in the earlier study, the following phases of participation were employed:

1. A period of 'free reading' (Gee 2001, p10): in order to allow readers their own time and space for ludic (playful/pleasurable) reading (Nell 1988), as well as to accommodate different rates of progress through the unique interfaces/designs of the pieces. Each reader was allocated one narrative, at random, but so that at least four readers saw each piece.

2. A simple post-reading questionnaire (see Miall and Kuiken 1995; Muylle et al 1999; Nell 1988; Wenz 1999; Gee 2001; Kjeldskov et al 2004) was sent to all participants. Slightly adapted to take account of developments in technology and terminology since the earlier study, the parameters for the multiple-choice questions were built from my literature review, and also from my pilot study. Space was provided in the questionnaire for open answers, as well as the pre-defined choices.

3. A focussed discussion, to pursue threads revealed in the questionnaires, which 12 respondents attended. Focus groups are commonly used in a range of research contexts (e.g. Puchta and Potter 2004, p7, and Nielsen 1997), and provide the reader-participants with the opportunity to elucidate more fully upon their initial responses to the narratives.

\subsection{Participant readers}

I called for 'people who love reading fiction and who would like try something new and maybe challenging in digital media'. These were also readers who were open-minded to the still-new 
experience of 'reading' fiction on a digital device. 30 readers of ages from 20 to 50+, volunteered to take part in the study, and 23 completed their questionnaire.

All of the participants were competent readers (Nell 1988). A competent reader for Nell is one who has read enough fiction to be aware of and react to the various narrative cues and plot conventions used by authors. I use 'competent' in an additional sense: all of the readers in my studies were familiar and comfortable with digital devices and could be called 'experienced' computer users (Ebling and John 2002). 100\% of the participants were regular PC/tablet users, using their digital devices for a range of applications such as e-books, games, multimedia 'apps', shopping, and information-browsing.

\subsection{Selected hyper-narratives}

There is no clear agreement as to where digital games end and hyper-literature begins: indeed 70\% of my participants said the experience of 'reading' their allocated narrative was like 'playing a game', while $57 \%$ said it was like 'solving a puzzle'. However, a key selection criterion for this study was the 'literariness' of the piece: narratives were chosen that display the features of novels, e.g. plot, characters and character development, thematic ambition, dialogue (Forster 1927; Watt 1957; Baldick 1990). In terms of the role taken by the audience in these pieces, the reader/user is in the role of a participating audience certainly, but not an avatar.

I chose one example from each year of the New Media Writing Prize, which, across the five, would display a wide range of interface designs, interactivity types, and use of multi-media, alongside text. None were text-only, and that in itself does reflect a shift in the nature of the art - there have been only two text-only shortlisted narratives (of 58) in the New Media Writing Prize since it began in 2010. The hyper-narratives chosen for study were:

Underbelly (Wilks 2010): 2010 winner, a poetic and highly visual piece, with a flowing, dynamic interface, using animation, video, voice-over, and a choice of endings facilitated by a 'wheel of fortune' device.

Welcome To Pine Point (Shoebridge and Simons undated): 2011 shortlister, a mediascrapbook, documenting the tale of a town that disappears. The containing visual metaphor of a scrapbook includes video, sound, photography, and text, with a 'narrator' who frames the whole piece in a story of journalistic investigation.

CityFish (Carpenter 2010): 2012 shortlister, short story/poem with a visually linear structure, and a plot that is essentially linear, but with the offer to hyper-jump forward and backward from time to time. Uses graphics, writtenl text, and video.

The Ghosts of the Yamaraja (Saunders 2013): 2013 student shortlister, which uses QR codes to enhance the online, interactive science-fiction story. This is mostly graphical, with a textual narration - but the QR codes unlock voice recordings of key characters.

PRY (Gorman and Cannizaro 2014): 2014 winner: an iPad app, which places emphasis on video and an intimate interaction with text. Has a linear chapter sequence, accessible via a conventional 'contents' page - but within chapters the narrative is fractured and often dependent on how the user interacts with text and video.

\section{The act of reading interactive fiction}

\subsection{The tension between 'book' and computer}

In answer to my question 'How do you feel about reading at a computer screen?', $60 \%$ of the respondents said it was 'no problem', but the remainder also said they preferred their 'comfy chair or bed', or that reading at a screen could hurt the eyes. Although a Kindle or iPad are more convenient for reading than a laptop or desktop PC, there is still a residual association between reading and the printed book. In the focus group, participants mentioned that the screen can tire the eyes, reading from a screen can seem like work rather than escapism, and the screen is associated with 'quick' reading (e.g. browsing or social networking). These preconceptions and practical considerations may still be influencing readers' attitudes towards hyper-literature (see also Mangen 2008).

Nonetheless, whereas, in 2010, 66\% said they would read another hypertext 'novel', in 2015, 95\% said they would try another new-media narrative, and the reasons given were encouraging for new-media writers: for example, the piece read was 'thematically rich and evocative'; reading the hyper-narrative was ‘an interesting experience', and a 'satisfying experience'; one reader said, 'I 
enjoyed the collaboration of music, narration, pictures, animations and videos,' and another said it 'felt like a more rounded experience than a book'.

\subsection{Reader expectations and hyper-narratives}

92\% said they liked to be challenged by the story they were reading, and $94 \%$ said they were prepared to go along with a difficult plot to see how it ended. The main reasons to give up on reading were 'uninteresting plot' or 'poor writing'. So, we might expect this group to be ready and able to remain undaunted by unfamiliar approaches to narrative delivery.

But only 22\% said they experienced the desired 'lost in a book' (Nell 1980) sensation. Some key expectations were often not fulfilled. 91\% said they expected interesting characters in a 'good read', but only 35\% said they found them in the pieces they read; $61 \%$ expected exciting action, but none found it; $97 \%$ expected emotional moments, but only $39 \%$ said they found those; only $17 \%$ said there was any surprise in the narrative; $13 \%$ said nothing at all carried them along. Clearly negative responses along these lines could be generated by reading unappealing fiction in print, but, given the selected narratives found favour with the New Media Writing Prize judges, these are at least unexpected results.

There were some positives: 'story development', 'interesting form', and 'narrative structure' were all mentioned in the questionnaire as aspects that carried readers along. But why did these narratives, seen as excellent examples by a panel of judges (see notes), significantly fail to deliver the expected reading pleasures to this group? The following sections offer some analysis:

- Narrative and design schemas

Douglas and Hargadon (2001), referencing Iser (1976), explain how a reader will use experience of schemas (frameworks of action, character arcs, genre-features etc.) from previously encountered narratives, to help them understand and interpret a narrative's development. In the previous study, hypertext fiction seemed to present few, if any familiar narrative schemas, making it difficult for readers to feel positive about the narratives they were encountering. The proliferation of links, the consequent breaking-up of narrative development, combined with unfamiliar and/or unintuitive interface designs all led those readers to only poorly appreciate any more formally literary qualities such as engaging writing, interesting characters, or dynamic plotting.

Clearly, any set of narratives, interactive or not, might receive poor reviews from a group of readers for aspects such as coherence of plot or interesting characters; but given that my previous work, and that of others, indicated a strong connection between interface, interactivity, and narrative enjoyment, I pursued these possible connections in the focus group discussion. Of The Ghosts of Yamaraja, one reader said that she felt she was 'jumping though all the hoops' rather than engaging with an unfolding narrative. Of $P R Y$, one reader noted that she 'didn't relate to the characters', possibly because the piece was 'quite distancing' and the reader felt she was 'grasping around' - thus also it was 'hard to have suspense'.

Other comments indicate, as in the previous studies, that interactivity can fight with narrative absorption: there was 'too much going on', it was 'more interesting when I was able to focus on one thing', and overall there was 'competition between elements', (cf Mangen 2008), and then the narrative schemas were not so effective in channelling the reader's attention into scenes, dramatic tensions, empathetic characterisation.

Schemas for the use of the medium itself were challenged by the hyper-fictions reported upon in 2006 and 2010. Not knowing how to make the narrative operate could become a major barrier to reading pleasure. However, the 2015 responses indicate that the readers now seemed not to be working so hard to adjust to the newness of form, structure and operation presented by hyper-narratives. Firstly, it is clear that readers have become more familiar with interacting in a wide range of ways: exploring the screen, clicking, pinching and swiping through pages on apps and websites are now very intuitive actions, almost becoming 'trivial'. 'I liked the way they were trying to be very interactive by their participation from the reader', was a representative comment from the respondents. Secondly, it would appear that writers and designers in this set are working within recognisable conventions for screen design and function. Storyspace, the pioneering software that delivered afternoon and many other hyper-texts, produced a user interface that did not look like anything else a reader would have seen on the web at the time - but a writer creating a narrative for the iPad, e.g. will certainly be creating functions that look and behave very much like those on any other touch screen device, from game apps, to shopping, to map-reading. For example, $92 \%$ said menus were easy to read and use, compared to $49 \%$ in 2010 . 
Where, in 1997, Murray argued that hypertext had not developed its own conventions to help readers through the mass of links and narrative multi-structures, now we might reasonably say that writers and designers are using more familiar signs and functionalities (operational schemas).

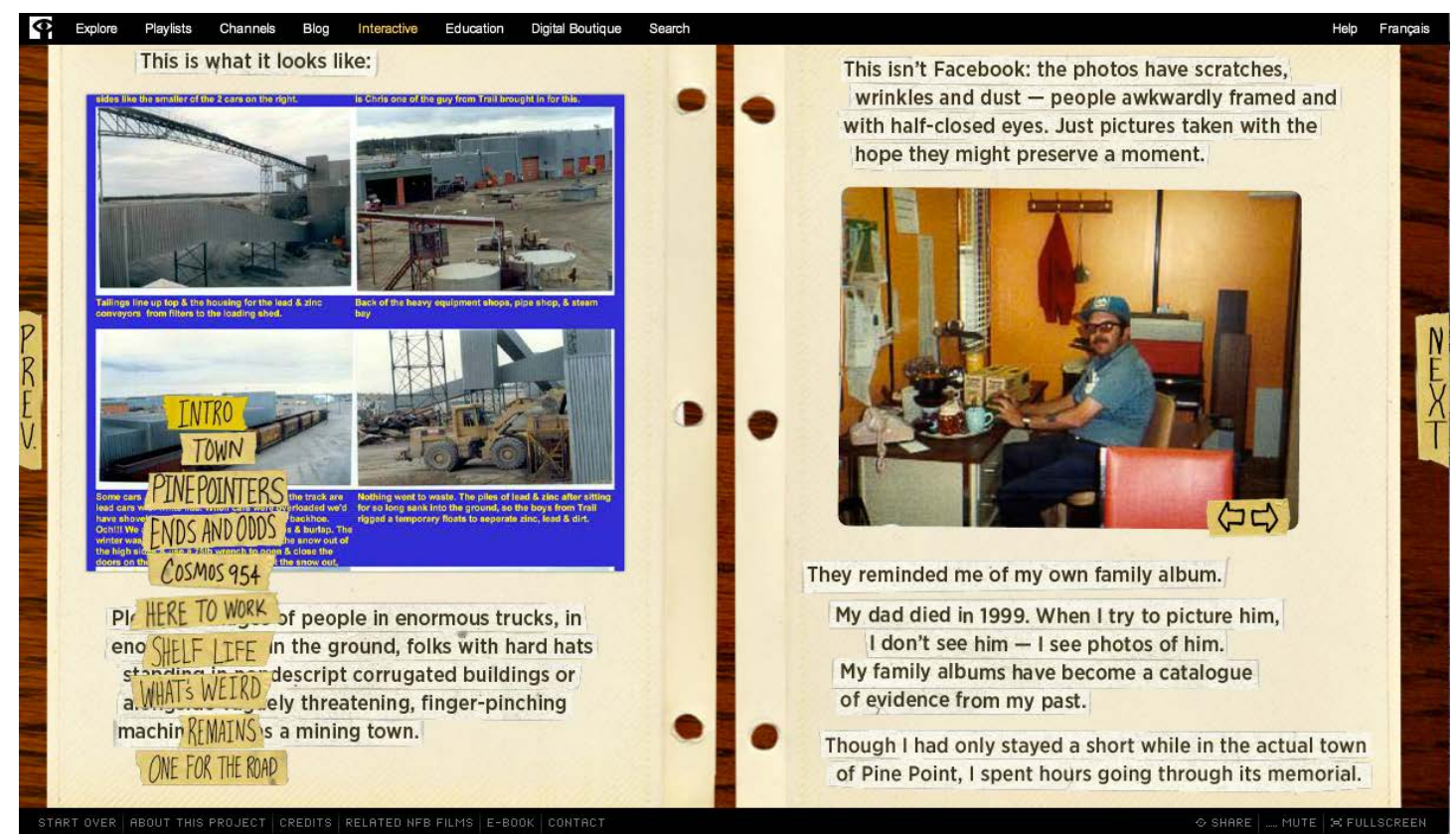

Figure 1: Welcome to Pine Point screenshot, showing navigation markers of various kinds.

Welcome to Pine Point, for example, uses very clear navigation cues: forward and backward arrows, with a continuously available menu which allows the reader to find any part of the narrative. This kind of schema for movement is very close to the ergonomics of books, websites, and apps, where location and directional markers are almost always deployed: readers thus know 'what to do'.

\subsection{The effect of volatile narrative structure}

In 2010, the strong overall response was that the hypertexts sampled were largely confusing and frustrating in terms of delivering a coherent and satisfying narrative. Comments such as 'pointless', 'no plot', 'no story', and 'disjointed' are representative of the overall feeling then from the readerparticipants. But in 2015, when asked about structural aspects readers seemed generally happier. In 2010, only 33\% said they could summarise the story to a friend, against $73 \%$ in 2015 . $72 \%$ readers found the plot to be either 'over-complex' or 'confusing' in 2010, against 39\% in 2015.

These numbers might seem to contradict the responses outlined above: readers' expectations were largely not met, and yet there were no major problems around key structural ingredients. A reasonable explanation of these responses, especially with the 2010 findings in mind, is that the narratives reviewed here are less complex structurally than the earlier set, with far fewer hyper-links which fracture plot and narrative development, and with less verbal text to read. So, in the narratives sampled, overall grasp of plot and story appear to be easier to attain, so fewer 'problems', even if the stories told were not always garnering rich plaudits.

The responses noted above are readers' perceptions of their experiences, not quantitative measurements of narrative complexity. Nonetheless it is fair to say that all of the narratives selected for this study, and indeed all of the New Media Writing Prize shortlisters and winners not included here, are indeed much less based on large numbers of hyper-linked words and hugely user-variable structures, than were the sample previously reported upon. An objection may be that I have simply chosen a selection of less-complex narratives for this study; but even if that is an influencing factor, the indication is that comprehension of plot and story-grasp issues diminish, when writers rein in the levels of user:plot possibilities.

\subsection{Closure}


Closure in narrative has been argued to be a key satisfaction for most readers: for example, Brooks (1984) argues that we read with the ending always in mind. Although that essentially Aristotelian conception has been challenged by some first-wave hypertext critics (Douglas 1994, 2000, Landow 1997) and hypertext writers themselves (Joyce 1997, Jackson 1997), my earlier study concluded that no matter how seemingly intriguing, complex and variable the narrative structure, readers did want closure, the sense that they had seen all there was to be seen (something noted also by Mitchell and McGee 2011), and that the narrated events had come to their conclusion.

In 2015, 78\% participants said that a satisfying conclusion was important to them. Whether or not the ending is pleasing will largely be a matter of the artist's skills, and the reader's preferences for example, Yamaraja was criticised by one reader because the final scene (a game-like action in which the user must fire a gun at an approaching monster) was predictable. Other readers felt that the choice of endings in Underbelly could work against the narrative staples of tension and release: one participant said, 'The ending was deeply unsettling, dropping into a bizarre future prediction which seemed entirely at odds with the rest of the piece...'

However, an aspect of closure where I observe a trend is in the design of an end-place. In the 2010 set, afternoon, These Waves of Girls (Fisher 2001), LOveOne (Malloy 1994), and Amelie (Ansotegui 2005), did not offer any end-place at all, which also muddied the sense of an ending for the reader. Underbelly, Yamaraja, Pine Point, and CityFish do all offer a clear end-place. So, whereas in the earlier study, there was significant consternation at the lack of clear endings and end-places, this was not an issue for the 2015 readers. In 2010, 54\% said they felt no sense of an ending, against 21\% in 2015. Writers in this set, and indeed in many other examples in the New Media Writing Prize shortlists since 2010, are designing in ways that allow the reader to know when the narrative is complete, thus removing at least one barrier to reading satisfaction. The reasons behind this apparent shift are not clear from this study, and it might be that writers have themselves realised that readers still want that 'traditional' satisfaction of the conclusion, or perhaps the first wave of radical structural experimentation seen in pieces such as These Waves of Girls or afternoon, has subsided, and older conventions are becoming prominent again in hyper-literature.

\section{The Interface}

\subsection{Navigation}

\section{- Free movement}

Nielsen (1990) argues that the reader needs to be able to move in step-by-step order, and out of order (using a map or contents page, for example) to anywhere in the web-space that they have so far experienced, or wish to see. Although Nielsen was not specifically thinking of narrative applications, I argue that readers/viewers/users wish to be able to move around an interactive space freely in order to apprehend the developing narrative, just as they can in the print environment or in a reading app, such as Amazon's Kindle.

$100 \%$ of participants said they found the navigation systems easy to learn across the five narratives examined, compared to $61 \%$ in 2010 . The 2015 pieces employ a range of systems for movement: Underbelly forces the reader forward; $P R Y$ has a menu to allow the reader to go to any section at will, but no linear forward/backward function within sequences of text; Pine Point offers forward/backward movement and a menu of sections (see Fig. 1); Yamaraja allows backward and forward steps; Cityfish is set out on the screen in a continuous 'ribbon' of images and text, so that any part of the narrative is available via simple scrolling.

As in 2010, if readers felt disoriented and/or stuck within the space or the narrative, their satisfaction and willingness to persevere with the piece both diminished: so, in the case of $P R Y$, for example, one participant became lost in the negative sense and 'eventually gave up'.

On the other hand, in 2010 (p86) my data indicated that 'a limited range of choices for movement will reduce the reader's cognitive overload, ... which in turn will lead to a more satisfying grasp of the narrative'. The confusing and disorienting plethora of choice found in pieces such as These Waves Of Girls is not seen in the designs of these more recent hyper-narratives: apart from Underbelly, which operates around a kind of poetic collage rather than a forward-moving plot, none of the pieces looked at here offer bewildering options for movement, via links within text, or between 'pages'. So, in Pine Point, it is always very evident where one is going when clicking on a link, and it is very easy to go back to the previous section if required. CityFish offers limited hyper-jumps to non-sequential parts of the story and where these occur readers expressed some confusion - but as one participant noted: 'I 
could get exasperated, but then I would suddenly start exploring again... you can easily re-engage again'.

A comment, from one reader of Underbelly, underlines how important free movement is, for reader-control and narrative coherence: 'I could move around the page but not around the story... I would like to be able to go backwards to clarify things.' The question for the writers is around balance between user-freedom and authorial design: Christine Wilkes forces the reader forward, toward a cataclysmic ending, and this is part of her narrative design - were she to offer the user freedom to backtrack, that narrative momentum might be lost.

- Orientation factors associated with story apprehension In 2010 I argued:

In hyper-narrative settings, story-space (site) orientation is not necessarily the same as narrative location. The extra facility (demand) of interactivity and the intangibility of the virtual book/space change the equation, so well-established in print, between 'site' location and narrative location’ (Pope 2010, p86).

Participants were asked in the questionnaire if they knew where they were in the site at all times, if they knew where they were in the story, and if they would be able to summarise the story to a friend (the ability to summarise used as a gauge of whether the reader had 'grasped' the underlying story by the end of their reading). I concluded from the data that poor site orientation would always lead to poor story orientation, which in turn leads to poor story apprehension.

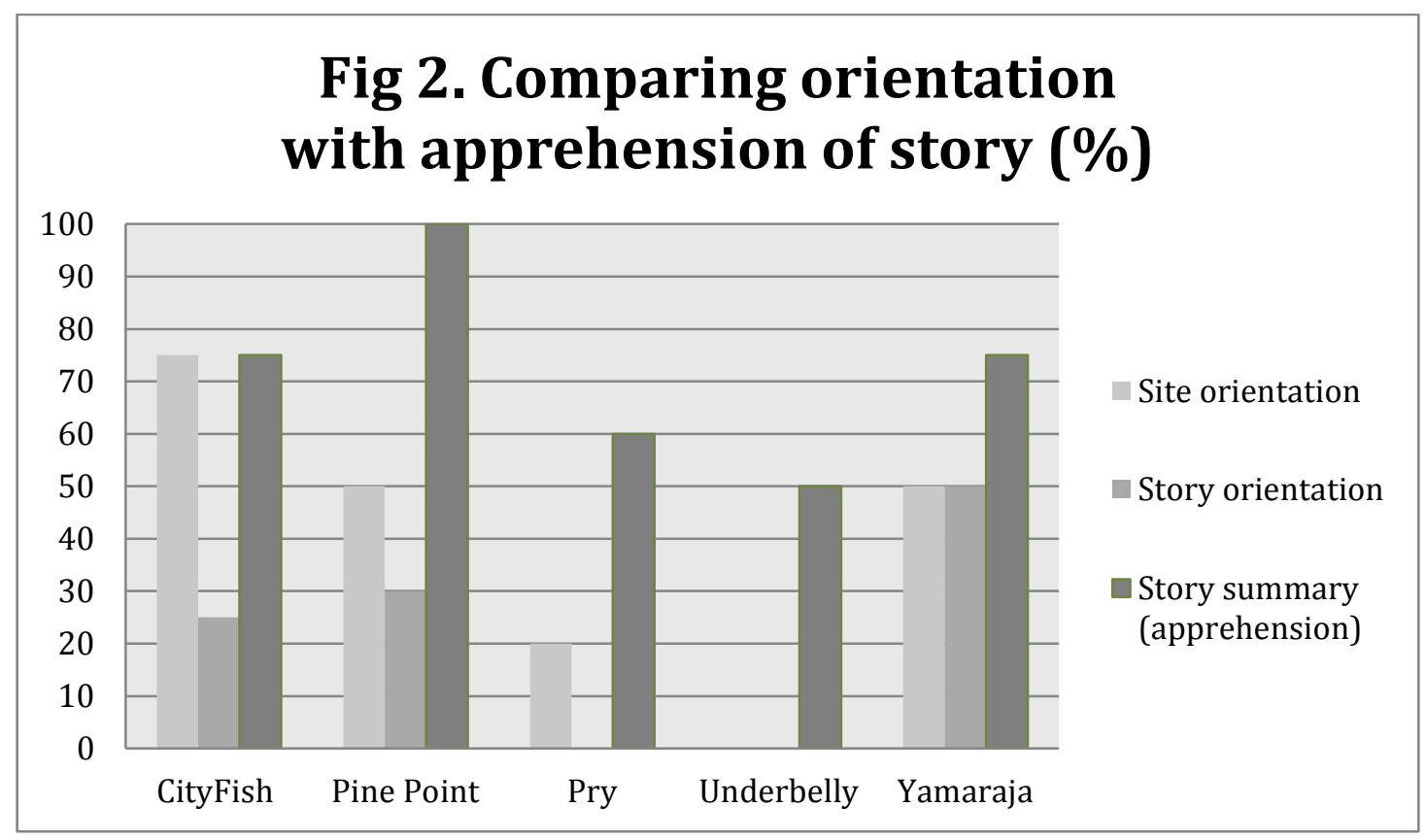

However, in the current study that correlation was not evident. The most striking example, as shown in Figure 2, is regarding Welcome to Pine Point: 50\% said they knew where they were in the site, only $30 \%$ said they knew where they were in the story, but 100\% could summarise the story. Seemingly, in this case, special and narrative orientation factors did not impact on overall story apprehension.

This requires some consideration, as it seems logical that being confused spacially and narratively would lead to an overall loss of story grasp - but the 2015 selection does not appear to show this. Influential factors might be that the stories being told in the 2015 selection are not as long, and certainly not as non-linear, in author-designed plot or reader-input to plot, as those offered in the likes of afternoon, These Waves of Girls, LOveOne, or 253 (Ryman 1996) from the 2010 sample. I also suggest that because much less written material is being used in the more recent sample, in proportion 
to visual and aural elements, the reader is more able to recall their 'reading' experience, and more able to 're-form' the underlying story from the various sections.

Clearly, more work should be done on the relationship between narrative and interface-design material, and story grasp/recall; but the indication here is that as long as hyper-links and interactions allow plot to develop coherently, then story-grasp will not be negatively affected, even where, at times, the reader might momentarily feel unsure of their place in the story or the 'site'. In the earlier study, the large amount of text, combined with large numbers of hyper-links, and consequent multiple pathways through the story-material, combined with unclear navigation and location markers, and lack of closure, was all too much for the readers; in 2015 the narratives selected were, for these readers, easier to navigate and easier to follow, and thus less likely to create a sense of disorientation.

\section{- Overview in large virtual spaces}

Nielsen (1990) argues that overview facilities should be offered in large virtual spaces, and hypernarratives are indeed liable to be large and potentially complex spaces, in which disorientation can easily occur: Figure 2 shows how few readers felt oriented within their story 'site'. Disorientation was often cited as a major barrier to story grasp and enjoyment in the earlier study, and was indeed a complaint of many hyper-sceptics (e.g. Miller 1998, and Birkerts 1997).

A homepage is a simple and familiar overview provision, which some digital narratives offer: however, only 57\% said that a home page is desirable - one reader of Underbelly said that it would have been 'good to have the option to go "home" ', but the findings are not decisive that a homepage is wanted or necessary for this set of readers.

A related issue, the desire in readers to know how much there is to read/see, appears of significance in an empirical study conducted by Mitchell and McGee (2011), who note that their participant readers sought to follow every hyper-link in order to have 'gained access to all possible information’ (p1943), in their quest for a satisfying ending. Facilities such as page/screen/section numbers, a progress indicator, or contents menu can provide useful detail toward this end. But although one participant said that she would choose a book on the basis of how much time she needed to invest, and that such an indicator would be very useful in the case of digital narratives too, there was no strong support for this facility as crucial to orientation or enjoyment amongst the focus group members.

Overall, the lack or presence of overview facilities does not seem to be directly connected to reader orientation or story grasp. CityFish uses the standard browser horizontal scrollbar to indicate how far along the story one has 'travelled', and this was seen as a simple and effective visual marker: $75 \%$ of the CityFish readers said they knew where they were in the site, and the same percentage could summarise the story. $P R Y$ has a homepage and a chapter menu, but its readers did not feel sure about their orientation in its space or its story. Underbelly has no location indicators but it does have a progress pie-chart, and none of its readers felt securely oriented in the site or its story. On the other hand, Yamaraja, which has no overview or location markers, scored better than Underbelly and PRY on site orientation.

The most 'successful' piece, in terms of positive responses to questions about interface design, was Pine Point, which also received highly positive responses for the experience of emotional moments, interesting characters, and narrative engagement: 'The general feeling of home and belonging, intermingled with the sadness of loss, was compelling', said one respondent. It has an array of overview tools: a homepage, persistent chapter menu, and clear location markers. $100 \%$ of its reader group were able to summarise the story. But only $30 \%$ of its reader group said they knew where they were in the story at any given moment, and only half said they knew where they were in the site.

So, although there are some indications both in empirical work and critical literature, that overview facilities are desirable, more work needs to be done around the relationship between overview tools, orientation, story grasp and reader enjoyment.

\subsection{Interactivity Design features}

- $\quad$ Balance between stimulus and distraction, and the media 'mix'

Campbell (2003) argued that a risk for writers of interactive fiction is that the attractions/distractions of a multi-media interface may detract from the absorbing act of reading. In this, Mangen (2008 p413) argues similarly:

...when the stimuli on the current screen do not contribute sufficiently to holding our attention, we tend to seek some sources to 'renew' it. (Mangen 2008 p409) 
If imaginative engagement with the narrative becomes pushed back to a secondary activity, either because there are so many interactive features to investigate, or because the narrative structure is also fractured and difficult to follow, a fatal loss of interest in the unfolding narrative can ensue. The 2015 selection appear to be blending media elements successfully, in terms of creating an appealing story-environment: 83\% said that multi-media elements enhanced the story-telling, compared with 53\% in 2010; 78\% said those elements enhanced their enjoyment, compared with only $42 \%$ in 2010.

Part of the reason for the positive shift is, of course, that the more recent narratives fully integrate appealing multi-media: the 2010 sample, and very many of the pioneering hyper-texts between 1987 and the early 2000s, were more often text-only or with limited media components which were not only less engaging technically, but also often used as a decoration rather than an integral element of the storytelling. Developments in technology have enabled writers/designers to much more fully exploit visual and aural possibilities, and we see this across the complete set of shortlisted entries in the New Media Writing Prize.

However, there is some evidence in 2015 that interactivity and media components can sometimes get in the way of reading/viewing/listening absorption:

Technical issues can break up the reader's attentive mood. Regarding Yamaraja, for half the participants, their QR reader app was not very sensitive and it took them too long to get the QR-driven material to load. The Quicktime movies, embedded into CityFish, would not play for everyone, and then a new plugin had to be acquired. Such technical bugs may be difficult for writers to prevent, but nonetheless they do take attention away from 'reading'.

Some operations simply did not maintain narrative impetus: Yamaraja’s QR codes require a second device, in order to access all the narrative, and was met with universal dislike. The QR codes 'took me out of the narrative' was a typical comment. Similarly, $P R Y$ 's ingenious text-ripping behaviour became boring for some: fun and impressive to begin with, but repetitive after a while, with not enough concomitant narrative payback.

If we wish 'readers' of hyper-narratives to be engaged, authors must strive to achieve a balance between interactivity that appeals operationally, and a narrative-building experience that is absorbing. Another participant said, regarding Underbelly, that there was sometimes 'too much going on', with unintended activation of animations, overlapping sounds and voices, and exploring the screen to find out what to do next. This comment from one of the CityFish group, who nonetheless enjoyed her reading, sums up the risk for writers, and supports Campbell and Mangen: "I do feel there is always the danger of the reader being distracted by the interaction, as I experienced with this one, the interactions made me feel like I was coming out of the story and I had to work hard to get back into it.'

The key is to ensure that every interaction, and every media component is essential to the developing narrative, and that the narrative itself is as well written and well plotted as it would need to be in any other, non-digital, non-interactive medium.

As I noted in 2010 (p88):

Balance between interface playing and reading absorption seems to depend on the optimum mix... of interface usability, (Campbell 2003; Gee 2001; Murray 1997; and Nielsen 1989,1990)... the psychological effort/reward balance (Aarseth 1997; Conklin 1987; Csikszentmihalyi 1975, 2002; Nell 1988)... and the interplay between reader and narrative structure (Iser 1976; Fish 1970, 1980; Brooks 1984; Douglas 2000; Miall 1999; Miall and Dobson 2001; Miall and Kuiken 1994, 1995; Murray 1997).

\section{- $\quad$ The balance between reader and author control}

The type of control offered in the 2015 selection is mostly of a kind that Ryan (2006) calls 'externalexploratory' (p 108), i.e. 'users navigate the display, but this activity does not make fictional history nor does it alter the plot' (p108). The role-playing immersion afforded by the big-franchise games is not generally offered by the kind of ludo-literary narratives which the New Media Writing Prize attracts and applauds. There is thus a potential tension between the ergodic demands made of the reader, and the narrative return.

My 2010 and 2015 findings support Murray (1997) and Ryan: authorial control and reader agency must be carefully balanced. Control and subordination to the author's design can clash, in readers' minds, where the offer of control excites the reader but the actuality of control becomes unrewarding effort, which thus might dis-engage the reader from the narrative. As one participant noted, 'if the effort added to the experience, people might be prepared to do that.'

What kind of control is positive, in terms of creating and sustaining an absorbed state in the reader? 'Good' control in the 2015 selection would be the option in Pine Point to watch videos which 
provided character colour: to activate these videos was seen as enjoyable because it added to the storyworld being built; but if one chose not to watch the video, the narrative still made sense. Moreover, one could watch the video again, or stop it at any moment. 'Bad' control was the requirement to activate QR codes in Yamaraja: if one chose not to activate the codes, some plot important detail was lost, but if one chose to activate them (and even if no technical hitches ensued), flow was disrupted. The control of text-splitting to reveal more text, in $P R Y$, was seen as initially interesting, but eventually dull, as narrative progression seemed to stall, highlighting how difficult a balance this is for authors to design.

Conversely, more control, deployed effectively, will enhance reader enjoyment, as explained by a reader of Underbelly: 'there needs to be a clear method of reading the parts of the story that you want to read, rather than things moving around that interrupt the narration you are listening to if you accidentally scroll over them'.

\section{- $\quad$ The design and functionality of links}

In 2010, 50\% of the readers said links were not easy to find, and that would be a cause of impeded absorption. I argued that, for screen-based fiction, screen-conventional linking iconography must be used, if the reader is not to be overcome with too many convention-breaking demands on their attention. To support my contention, I cited studies and discussions from human-computer interface usability studies (e.g. Pace 2003, Thimbleby 2000), from Conklin's (1987) conceptualising of cognitive overload, from Nell's (1988) theory of the effort-absorption relationship in ludic reading, and from Csikszentmihalyi’s flow research $(1975,2002)$.

In 2015 the situation is more positive: only 13\% said links and hotspots were not easy to find. The reasons for this might be that, by now, readers are simply more familiar with interactivity in their everyday use of digital devices; and it might be that writers are using more conventional indicators to make sure links are apparent. The ubiquitous cursor 'hand' icon, for example, is a sure sign of a hotspot of some kind, familiar to everyone who uses digital media.

Secondly, and inextricably connected to the first point, links are highly significant in the telling of the story (see also Calvi 1999, and Kendall and Réty 2000): links are a navigation tool and, simultaneously, story-telling device. The structure of links may be a rhizome-like network of choices enacted by the reader, or a simple linear 'page-turning' functionality: how the links are organised by the author will impact on the reader's sense of the story unfolding. When I asked readers, 'Did the links lead you to places that made sense and/or kept the story moving?” $77 \%$ said yes, compared to only $47 \%$ in 2010 . In 2010, $41 \%$ of readers said the activity of following links added to their enjoyment, while $44 \%$ said it was a disruptive activity, with $15 \%$ answering in the neutral. In 2015 52\% said following links added to their enjoyment, only $20 \%$ said the activity of following links was disruptive, with $28 \%$ neutral. In the discussion there was no strongly negative comment about the need to activate hot-spots or trigger links on text: it is seen as a 'natural' activity for the readers in this group.

\section{Conclusions: How far down the digital road have we come?}

This paper has discussed a small selection of recent well-thought-of hyper-narratives in order to evaluate how far recent hyper-narratives are overcoming acknowledged problems for readers, evident in the experience of reading in earlier hyper-narratives.

Although I have noted some encouraging shifts from several negatives found in my earlier study, there are still challenges to be met for writers/designers, in order to facilitate immersive, satisfying narrative experiences for their readers/users. Hyper-literature is, after all, an emerging art-form, still developing conventions for interface design and hardware usability, for example; and still exploring possibilities for multi-media incorporation, and narrative structures.

The manifestation of the virtual space, (Iser 1976), where the art comes to life in the imagination of the reader, seems still to be dependent upon a skilful blending of a very accessible, 'invisible' interface, smooth integration of hyper-links and interactive elements, and meaningful utilisation of multi-media components. If those elements are all working in harmony, the work of art has its chance to engage and stimulate 'reading' pleasure.

Of course, this study focusses on a small sample of narratives, and a small well-disposed and knowledgeable reader group, and so generalisation of conclusions is cautiously offered.

I am aware that there are many other hyper-stories across Ensslin’s (2014) L-L continuum, which might provide different reader responses (because the interface designs are seen as more or less usable, perhaps, or because the genres of the pieces chosen better suited the preferences of the readers).

A much larger reader sample, controlled for variables such as gender, age, and media preferences, could reveal more fine-grained details around the connections between interface design, interactivity, and reader satisfaction. 
Thus further reader-response studies will inevitably need to be undertaken as the form and the supporting technology develop. However, the patterns of response observed here, considered alongside the findings from my earlier studies, do provide useful indications of correlations between design factors and reader satisfaction.

It is not my intention to suggest that all hyper-writers should aim to make their work 'mainstream' or an 'easy read', or that hyper-narratives need achieve commercial success to be of value. As we know, many forms of narrative fiction in print produce a distancing effect, where, for example, Iserian gaps and blanks, and postmodern narrative twists and genre clashes can create challenge and even bewilderment. There are many examples of such narratives across media that are enjoyed by audiences: think of a non-linear film such as Mulholland Drive, or a postmodern novel such Slaughterhouse Five. There is a large body of critical literature distinguishing between the almost effortlessly immersive pleasures of reading (see Nell 1988) and the more 'satisfying' but demanding joys of challenge and defamiliarisation (see for example, Barthes 1973; Miall. and Kuiken1994) So, just as the novel has accommodated realism, magical-realism, modernism, postmodernism, the niche and the popular, so hyper-fiction can embrace many possibilities and audiences.

But, some of the scepticism around hyper-fiction's ability to arouse engagement and reading absorption (Birkerts 1997, Mangen and van der Weel 2015, Miall 1998, 1999, 2003, Miller 1998) is still seen in responses from this current group of readers, and this well-regarded selection of hyper narratives. I therefore do argue that most readers will be looking for the narrative 'hits' of character development, plot dynamics, closure, and so on that they are used to and enjoy, and they will want the interactivity to be as intuitive and unintrusive as all their other digital applications, from shopping to social media. And therefore, key design elements must all be carefully considered with narrative development in mind, because pleasure gained from narrative development is the crucial factor in generating conditions for flow in the reader, that absorbing balance of effort and reward.

For the future, what I observe in this study, but also from reading and considering many other digital interactive narratives available now, is that app-based hyper-literature is becoming more prevalent, and that the narrative forms are becoming less complex, in fact less challenging, with more eye-catching visuals and interactions. In future, as the software and the hardware develop, I imagine a blossoming of a wide range of readily accessible narratives, which achieve that goal noted by Ryan (2006, p99): 'a seamless... convergence of bottom-up [reader] input and top-down [author] design to produce well-formed narrative patterns'. For now, nonetheless, there are still some issues to be considered by academics, students, writers and teachers, as they all strive to understand how readers react to hyper-literature.

So, to end, I offer a summary of the elements of narrative design, which matter for readers. The key 'guidelines', revised from my earlier studies, are in bold italics, followed by elucidation:

- Writers need to 'ease' readers into new forms using carefully employed schema signs. There is evidence that writers and designers are designing within a more familiar ergonomic field, as readers use interactive functionality and multi-media modes in more and more 'everyday' activities. Readers are largely familiar with digital interactivity schemas and are not much troubled by navigating, clicking, tapping or swiping. Some problems were nonetheless evident around narrative keys such as plot schemas and character development, and although such issues might not always be linked to design features, the indications are that writers should carefully consider the impact that interactivity, interface design, and the mediamix might have on narrative progress.

- $\quad$ Links, when followed, must progress the narrative.

The hyper-linking structures seen in this sample are certainly much less complex than in the pioneering hyper-texts, but there is still evidence that readers have only limited tolerance for unclear narrative development (see also Mitchell and McGee 2011, and Kendall and Rety 2001). For example, $P R Y$ 's highly non-linear narrative created too-strong a distancing effect, even if its fractured structure artistically mirrored the psyche of the main character.

- Effective free movement in hypertext should enable the reader to go anywhere they want in the site, but more importantly to go wherever they want to in the narrative.

Restricted movement was not seen as a problem if the story is developing engagingly, for example as in Yamaraja. Where the narrative appears not to unfold, and movement is over- 
restricted, e.g. as in Underbelly, for some readers, less inclined to explore, there can be frustration and ennui.

- Navigation and orientation systems should allow the reader to know where he/she is in the 'site' and in the narrative.

One participant noted that there is a 'rhythm' to a book or a film: the audience knows where it is in the narrative, it can sense the movement through acts, or can see the progress through chapters. This rhythm (facilitating orientation) often seemed hard to discern, for readers in the previous and current studies. Overview facilities can assist in this narrative orientation, but as noted, the relationship between site and narrative orientation is unclear, and further work with readers is needed.

- Interface design needs to be integral to the narrative at an operational and metaphorical level; the interface must be simultaneously appealing and non-distracting

It is worth noting here that $43 \%$ said they were bothered or irritated by the interface, and this is only a very slight improvement upon the 2010 figure of $47 \%$ for the same question. In both studies the slight majority said the interface did not intrude, but there is clearly a significant portion of the audience that finds the interface a chore to be dealt with. Only 30\% said the interface became second nature ('as turning a page in a book would be'), and although this is an improvement upon the $14 \%$ from 2010 , there is still work to be done in this regard, if we go along with the notion that unrewarding distraction from the narrative itself is a negative factor in the effort-reward equation. And one participant said, 'I wish we could fast forward about 15 years when all this is as effortless as turning a page'.

- Web/app design conventions for interactivity should be used as far as possible, in order to minimise the levels of non-trivial effort required, and thus making access to the narrative as straightforward as possible for the reader.

With the advent of touch-screen devices, and the expansion of apps as the platform for much digital activity, new conventions for interactivity have emerged, e.g. swipe, tap, pinch, sweep, etc. However, interactivity design should as far as possible offer behaviours that readers are at least reasonably familiar with, so that non-trivial activity does not expand into cognitive overload.

- Interactivity should be kept at a level which enhances and does not impede reading absorption; interactivity should be clearly presented, so that it has a chance of being simultaneously engaging and cognitively undemanding.

Some forms of interactivity are seen as valuable and some merely decoration, or even an inconvenience. I argue that telling the story must be at the heart of all interactivity design. Comments in the discussion flesh out the point: 'it's difficult to get a balance between interactivity and narrative', 'that gap between exploration and exasperation is incredibly narrow'. I thus argue that writers do still need to think carefully, as one participant noted, about the 'very good reason to use interactivity'.

- Control and choice must only be offered where they are helpful for navigation or essential for the development of the narrative.

Closely related to the previous point, the picture from my participants in 2015 suggests that more thought still has to be given to how and why user input is built into the form and content of hyper-literature. Control of narrative-significant elements is seen as needful, but there is an optimum level of control, which can turn into a negative effort if it is not fluent, fails to operate without error (Roth et al 2011), or is seen to be unnecessary.

(8,255 words including all headings after main title)

\section{Bibliography}

AARSETH, E. (1997) Cybertext: Perspectives On Ergodic Literature, Baltimore: John Hopkins University Press 
ANSOTEGUI, I. (2005) Amelie, unpublished Bournemouth University Masters project

BALDICK, C. (1990) Oxford Concise Dictionary of Literary Terms, Oxford, Oxford University Press

BARTHES, ROLAND, 1973, The Pleasure of the Text, Paris, Editions du Seuil (edition cited 1990, Oxford, Basil Blackwell)

BIRKERTS, S. (1997) 'Digital Storytelling: Is It Art?’ in Synapse, URL (consulted 27/02/02, but not accessible 3/1/16): http://hotwired.wired.com/synapse/braintennis/97/31/index0a.html)

BOLTER, J. D. (2001) Writing Space $2^{\text {nd }}$ ed., Mahwah, NJ: Lawrence Earlbaum Associates.

BRADFIELD Company, The, (2006-2015) Inanimate Alice, URL (consulted 22/4/16):

http://www.inanimatealice.com/

BROOKS, P. (1984) Reading for the Plot, Oxford: Oxford University Press.

CAMPBELL, A. (2003) Interviews on Dreaming Methods Website, URL (consulted 28 July 2009, but not accessible 22/4/16): http://

www.dreamingmethods.com/uploads/dm_archive/objects/html/i_object_914413_839840.html

CALVI, L. (1999) ' "Lector in Rebus": The Role of the Reader and the Characteristics of

Hyperreading', in Proceedings of the Tenth ACM Conference on Hypertext and Hypermedia, New

York, ACM Press, pp101-109

CARPENTER, J.R. (2010) CityFish, URL (consulted 23/12/15): http://luckysoap.com/cityfish/

CONKLIN, J. (1987) ‘Hypertext: An Introduction and Survey’, in IEEE Computer, Volume 2, Number 9, September 1987, pp17-4

CSIKSZENTMIHALYI, M. (1975) Beyond Boredom And Anxiety, San Francisco: Jossey-Bass

CSIKSZENTMIHALYI, M. (2002) Flow, London: Rider

DOUGLAS, J. Y. (2000) The End of Books, or Books Without End? Ann Arbor: University of Michigan Press

DOUGLAS, J. Y. (1994) 'How Do I Stop This Thing?’ Closure and Indeterminacy in Interactive Narratives', in Hyper/Text/Theory ed. George Landow, Baltimore, John Hopkins University Press, pp 159-188

DOUGLAS, J. Y., and HARGADON, A. (2001) 'The Pleasures of Immersion and Engagement: Schemas, Scripts and the Fifth Business' in Digital Creativity Volume 12, Number 3, pp153-166

EBLING, M. R., and JOHN, B. E., (2000) 'On the Contributions of Different Empirical Data in Usability Testing', in Symposium on Designing Interactive Systems archive: Proceedings of the Conference on Designing Interactive Systems: Processes, Practices, Methods and Techniques, ACM Press, New York: USA, pp289-296.

ENSSLIN, A., (2014) Literary Gaming, Cambridge, Mass: MIT Press

FISH, S. (1970) 'Literature in the Reader: Affective Stylistics', in New Literary History, Volume 2, pp $123-63$.

FISH, S. (1980) Is There a Text in This Class? The Authority of Interpretive Communities, Cambridge, Mass: Harvard University Press.

FISHER, C. (site launch February 2001) These Waves of Girls, (URL consulted 24/12/15):

http://www.yorku.ca/caitlin/waves/navigate.html 
FORSTER, E.M. (1927) Aspects of the Novel, Edward Arnold; edition cited 1977 Middlesex, Penguin Books

GEE, K. (2001) 'The Ergonomics of Hypertext Narrative: Usability Testing as a Tool for Evaluation and Redesign', in ACM Journal of Computer Documentation, Volume 25 Issue 1, Feb. 2001, URL (consulted 3/1/16):

http://dl.acm.org/citation.cfm?id=383950\&CFID=572557549\&CFTOKEN=60356545

GORMAN, S., and CANNIZARRO, D., PRY, (2014), app - Tender Claws LLC

HOLLAND, NORMAN, (1975) 5 Readers Reading, New Haven, Yale University Press

ISER, W. (1976) The Act of Reading, (English translation cited 1978, London; Routledge and Kegan Paul)

JACKSON, SHELLEY, (1995), Patchwork Girl, Watergate: Eastgate Systems.

JACKSON, S. (1997) 'Stitch Bitch: The Patchwork Girl', in Transformations of the Book, MIT October $24^{\text {th }}$-25th 1997, URL (consulted 3/1/16): http://web.mit.edu/m-it/conferences/book/index_papers.html

JOYCE, M. (1987) afternoon, a story, Watergate: Eastgate Systems

JOYCE, M. (1997) ‘Nonce Upon Some Times: Rereading Hypertext Fiction’ in Modern Fiction Studies Volume 43, Number 3, p579-597

KENDALL, R. and RETY, J.-H. (2000) 'Toward an Organic Hypertext' in Proceedings of the Eleventh ACM on Hypertext and Hypermedia, New York: ACM Press, p161-170

KJELDSKOV, JESPER; SKOV, MICHAEL B.; STAGE, JAN, (2004) 'Instant data Analysis: Conducting Usability Evaluations in a Day’, in Proceedings of the Third Nordic Conference on Human-Computer Interaction, New York: ACM Press, p233-240

KLIMMT, C.; ROTH, C.; VERMEULEN, I.; VORDERER, P.; ROTH, F.S., 2012, 'Forecasting the Experience of Future Entertainment Technology: “Interactive Storytelling” and Media Enjoyment', in Games and Culture, 7 (3), p187-208

KOENITZ, H., HAAHR, M., FERRI, G., SEZEN., I.T., (2013) 'First Steps Towards a Unified Theory for Interactive Digital Narrative’ in Eds Pan et al, 2013, Transactions on Edutainment $X$, p20-35.

LANDOW, G. (1997) Hypertext 2.0, Baltimore: Johns Hopkins University Press

LIVINGSTONE, SONIA, (2004) 'The Challenge of Changing Audiences. Or, What is the Audience Researcher to do in the Age of the Internet?’ in European Journal of Communication Volume 19, Number 1, pp75-86

MALLOY, J. (1994) LOve0ne, URL (consulted 3/1/16):

http://www.eastgate.com/malloy/welcome.html

MANGEN, A., (2008) 'Hypertext fiction reading: haptics and immersion', in Journal of Research in Reading, Volume 31, Issue 4, pp 404-419, November 2008

MANGEN, A., and van der WEEL, A., (2015) 'Why Don’t we Read Hypertext Novels?', in Convergence, May 2015, URL (consulted 23/12/15): http://con.sagepub.com/content/early/2015/05/22/1354856515586042.full

MIALL, D. S. (1998) The Hypertextual Moment, URL English Studies in Canada, 24 (June 1998), pp157-174. 
MIALL, D. S. (1999) ‘Trivializing or Liberating? The Limitations of Hypertext Theorizing’, in Mosaic Volume 32 Issue 2, pp157-172, URL (consulted 3/1/16):

https://wwwapps.cc.umanitoba.ca/publications/mosaic/common/issue/index/60\#

MIALL, DAVID S., 2003, 'Reading Hypertext - Theoretical Ambitions and Empirical Studies’, presented to REDES group, University of Munich December $16^{\text {th }} 2003$. URL (consulted 22/4/16): http://computerphilologie.uni-muenchen.de/jg03/miall.html

MIALL, D. S. and DOBSON, T. (2001) 'Reading Hypertext and the Experience of Literature', Journal of Digital Information Vol 2, No 1, URL (consulted 19/4/16):

https://journals.tdl.org/jodi/index.php/jodi/article/view/35/37

MIALL, D. S. and KUIKEN, D. (1994) 'Beyond Text Theory; Understanding Literary Responses' in Discourse Processes, Volume 17, 1994, pp 337-352, URL (consulted 22/4/16): http://www.ualberta.ca/ dmiall/reading/BEYOND_t.htm

MIALL, D. S. and KUIKEN, D. (1995) ‘Aspects of Literary Response: A New Questionnaire’, in Research in the Teaching of English, Volume 29, 1995, pp37-58, URL (consulted 21/4/16): https://www.ualberta.ca/ dmiall/reading/LRQ_95.htm

MIALL, D. S. and KUIKEN, D. (1999) 'What is Literariness? Three Components of Literary Reading', in Discourse Processes, volume 28, 1999, pp121-138, URL (consulted 22/4/16):

https://www.ualberta.ca/ dmiall/reading/Literariness.htm

MILLER, L. (1998) 'www.claptrap.com’ in New York Times Book Review, March $15^{\text {th }} 1998$, URL (consulted 3/1/16): http://www.nytimes.com/books/98/03/15/bookend/bookend.html

MITCHELL, A., and McGEE, K., (2011) 'Limits of Rereadability in procedural Interactive Stories', in CHI '11 (Proceedings of the SIGCHI Conference on Human Factors in Computing Systems), New York: ACM Press, p1939-1948

MOULTHROP, STUART, (1991), Victory Garden, USA, Eastgate Systems.

MURRAY, J. H. (1997) Hamlet on the Holodeck, Cambridge Mass.: MIT Press

MUYLLE, S., MEONART, R., and DESPONTIN, M. (1999) 'A Grounded Theory of World Wide Web Search Behaviour’, in Journal of Marketing Communications, volume 5, pp143-155

NELL, V. (1988) Lost in a Book - The Psychology of Reading for Pleasure, New Haven: Yale University Press

NIELSEN, J. (1989) 'The Matters That Really Matter For Hypertext Usability’ in Proceedings of the Second Annual ACM Conference on Hypertext, New York, USA, ACM Press, pp 239-248

NIELSEN, J. (1990) 'The Art of Navigating Through Hypertext' in Communications of the ACM, March 1990, Vol 33, No. 3 pp 296-310.

NIELSEN, J., (1997), The Use and Misuse of Focus Groups URL (consulted 22/4/16): https://www.nngroup.com/articles/focus-groups/

NIELSEN, J.; CLEMMENSEN, T.; YSSING, C., (2002) 'Getting Access to What Goes on in People's heads?: Reflections on the Think-Aloud Technique', in Proceedings of the Second Nordic Conference on Human-Computer Interaction, New York: ACM Press, pp101-110

PACE, S. (2003) 'A Grounded Theory of the Flow Experiences of Web Users', in International Journal of Human-Computer Studies, Volume 60, Number 3, March 2004, pp327-363.

PETERSEN, M. G., (1998) 'Towards Usability Evaluation of Multimedia Applications', in Crossroads - Special issue on multimedia systems, Vol 4 issue 4 (Spring 1998) New York: ACM Press pp3-7 
POPE, J. (2006) ‘A Future For Hypertext Fiction’, in Convergence, Volume 12, Number 4, pp447-465

POPE, J. (2010) ‘Where Do We Go From Here?’, in Convergence, Volume 16, Number 1, pp75-94

PUCHTA, C. and POTTER, J. (2004) Focus Group Practice, London: Sage

PUNDAY, D. (2011) 'From Synesthesia to Multimedia: How to Talk about New Media Narrative’, in Page, R. and Thomas, B., eds. 2011. New Narratives: Stories and Storytelling in the Digital Age. Lincoln: University of Nebraska Press, pp19-34.

RICHARDS, I.A. (1929) Practical Criticism, New York: Harcourt Brace and Co.

ROTH, C.; KLIMMT, C.; VERMEULEN, I. E.; VORDERER, P., (2011) 'The Experience of Interactive Storytelling: Comparing "Fanreheit” with "Façade”, in Entertainment Computing - ICEC 2011, pp13-21

RYAN, M.-L. (2006) Avatars Of Story, Minneapolis: University of Minnesota Press

RYMAN, G. (1996) 253, URL (consulted 21/4/16): http://www.ryman-novel.com

SAUNDERS, J., (2013) The Ghosts of Yamaraja, URL (consulted 20/4/16): http://jsportfolio.co.uk/yamaraja\%20home.html

SHOEBRIDGE, P., AND SIMONS, M., (undated) Welcome to Pint Point, (URL (consulted 23/12/15) http://www.pinepoint.nfb.ca/\#/pinepoint

THIMBLEBY, H. (2000) 'Permissive User Interfaces', in International Journal of Human-Computer Studies, Volume 54, Issue 3, March 2001, pp333-350

THURY, E. M. (1998) 'Analysis of Student Browsing Behavior: Implications for Designing and Evaluating Web Sites' in ACM Special Interest Group archive, Proceedings of the $16^{\text {th }}$ international conference on computer documentation, New York: ACM, pp265-270

WATT, IAN, 1957, The Rise Of The Novel, Chatto and Windus (edition cited 1977, UK: Penguin Books Ltd)

WENZ, KARIN, (1999) Patterns of Hypertext and their Impact on Reading Activities, URL (consulted 10/11/04; inaccessible 22/4/16) http://www.uni-kassel.de/fb8/privat/wenz/hypertext

WILKS, C., (2010) Underbelly, URL (consulted 23/12/15): http://crissxross.net/elit/underbelly.html

WRIGHT, PETER C. AND MONK ANDREW F., (1990) 'The Use of Think-Aloud Evaluation Methods in Design’, in SIGHI Bulletin January 1991, Vol 23 Number 1, pp55-57.

ZYNGIER, SONIA, (2003) 'What is Literature Really? A Corpus-Driven Study Of Students' Statements', in Style, Spring 2003, URL (consulted 3/1/16):

http://www.jstor.org/stable/10.5325/style.37.1.14?seq=1\#page_scan_tab_contents 